\title{
Endarterectomy for asymptomatic carotid artery stenosis
}

\author{
Reasonable doubt justifies randomisation
}

European and North American clinicians have always differed in their management of carotid artery disease. ${ }^{1}$ Carotid endarterectomy is one of the commonest vascular procedures in North America, with over 360 operations per million population being performed each year. ${ }^{1}$ Meanwhile, despite the fact that the first carotid reconstruction was performed in Britain, ${ }^{1}$ selection for the procedure in Europe has been sporadic. British data for 1993-4 confirm that fewer than 40 carotid endarterectomies are performed per million population per year (personal communications from Department of Health, England; NHS Information and Statistics Division, Scotland; and Department of Health and Social Services, Northern Ireland, 1995).

Two major multicentre trials, the North American symptomatic carotid endarterectomy trial and the European carotid surgery trial, both published in 1991, have helped to define the role of carotid endarterectomy in patients with symptoms, such as transient ischaemic attacks and non-disabling strokes. ${ }^{23}$ In symptomatic patients with an internal carotid artery stenosis of greater than $70 \%$, endarterectomy produced a $75 \%$ reduction in rates of stroke over two to three years when compared with best medical treatment. These trials meant that carotid endarterectomy became a member of that small group of preventive surgical procedures that have withstood the test of a randomised controlled trial.

Neurologists' lack of confidence in the outcome of carotid endarterectomy has contributed to low rates of referral in Europe. ${ }^{1}$ The benefit to patients with symptoms is acknowledged, but the impact of the operation on preventing stroke in the population has been challenged, as highlighted recently in the BMf. ${ }^{4}$ Health service statistics suggest that the provision of endarterectomy for symptomatic patients is not uniform across the country. Given that Britain cannot optimally provide for patients with symptomatic carotid stenosis, should we be promoting the operation for patients with asymptomatic disease?

To be convinced that surgery benefits such patients we need to know that the risk of perioperative stroke and death in patients undergoing endarterectomy is lower than the risk of ipsilateral stroke in patients managed conservatively. In Britain and the United States 200 strokes occur per 100000 people each year despite best medical treatment, which includes control of hypertension and diabetes, stopping smoking, and antiplatelet treatment. ${ }^{5}$ Twenty to thirty per cent of these events may be related to carotid disease. ${ }^{5}$ Only $10-20 \%$ of all ischaemic strokes will be preceded by transient ischaemic attacks, amaurosis fugax, or minor strokes. The great majority occur in patients with asymptomatic carotid artery disease, in whom the annual rate of ipsilateral stroke is about $2 \%$ a year. ${ }^{67}$ The morbidity and mortality from carotid endarterectomy in these patients is unlikely to be higher than the $0-6 \%$ reported in symptomatic patients. ${ }^{89}$ As for the risk of stroke in asymptomatic patients who are managed conservatively, this is likely to be highest in those with tight stenoses, as is the case in symptomatic patients. If the annual risk of stroke in patients with more than a $70 \%$ stenosis is greater than the risk of perioperative stroke then endarterectomy may well have a role in their management.

Another unanswered question is whether outcomes are influenced by the clinical circumstances in which the asymptomatic stenoses are found. For example, the risk of stroke may be greater if the contralateral internal carotid artery is occluded, and the influence of a stenosis on the risk of perioperative stroke after major surgery, including coronary artery bypass, is uncertain. Other concerns include the risk associated with a stenosis and a symptomatic ipsilateral ischaemic event separated by more than six months and "asymptomatic" stenoses in which infarcts are detected on cerebral imaging.

\section{Conclusive evidence is lacking}

Early studies in asymptomatic patients have been inconclusive because of the small numbers of patients and other methodological problems. An early non-randomised study by Thompson et al helped to establish carotid endarterectomy in North America. ${ }^{9}$ Of 1286 carotid endarterectomies performed over 20 years, 167 were performed on 132 patients, with no perioperative deaths. Postoperatively, few of these highly selected patients had transient ischaemic attacks or strokes, and they suffered five times fewer events than a control group of less fit patients with asymptomatic carotid bruits. The authors concluded that "asymptomatic carotid bruits may be potential stroke hazards, the risk of which can be significantly reduced by appropriately applied endarterectomy." Three randomised studies of surgery for asymptomatic carotid artery disease failed to confirm this suggestion, ${ }^{11-13}$ and other studies suggested that an asymptomatic bruit was no more than a marker of atherosclerosis. The incompletely randomised carotid artery stenosis with asymptomatic narrowing: operation versus aspirin (CASANOVA) study showed no benefit from surgery, ${ }^{10}$ but all patients with stenoses of greater than $90 \%$ underwent operation. In the Mayo Clinic's randomised study recruitment was stopped when the surgical group showed high rates of postoperative myocardial infarction. ${ }^{11}$ In a small study on American veterans Hobson et al reported a benefit from surgery, but the message was clouded by anomalies in the subgroups and reservations about the classification of neurological events. ${ }^{12}$

The lack of conclusive evidence for endarterectomy in asymptomatic disease led to the establishment of two multicentre randomised studies, the asymptomatic carotid atherosclerosis study (ACAS) and its European counterpart, the asymptomatic carotid surgery trial (ACST). Results from the ACAS group have recently become available and suggest that, for internal carotid artery stenosis $>60 \%$ in asymptomatic patients, endarterectomy is beneficial. ${ }^{13}$ This is the first large randomised study to reach this conclusion. The ACST trial is still in progress, and recruitment to the ACAS trial has stopped after statistical analysis of the end points stroke and mortality. Although this study contains 1662 patients, of whom 828 were randomised to surgery, patients were selected by the participants and were not consecutive.

The study is not free from methodological anomalies, with $9 \%$ of the study group not receiving the allocated treatment, including 101 patients in the surgical arm who did not have surgery and 45 patients in the medical arm who had endarterectomy. The patients in the medical arm who had 
endarterectomy had not become symptomatic. The statistical analysis by intention to treat seems to balance this noncompliance. Median follow up is short ( $2 \cdot 7$ years), and the five year rates of stroke and death combined, for both the surgical $(4.8 \%)$ and the medical groups $(10.6 \%)$, are Kaplan-Meier projections. The efficacy of endarterectomy in women is one third less than that in men owing to more perioperative complications in women. There does not seem to be an increased risk of stroke with increasing degree of stenosis, which is a feature of symptomatic trials, but the numbers in the subgroups are relatively small. Overall there is no difference between surgical and medical groups in the outcome of any major stroke or death (116 medical patients, 100 surgical patients).

\section{Need for selection and caution}

Despite these methodological flaws the study has clear messages for any clinician intending to offer surgery to patients with asymptomatic disease: since duplex ultrasound scanning had a positive predictive value of $95 \%$ and $x$ ray contrast angiography carried a risk of stroke of $1.2 \%$, selection should be by safe non-invasive duplex investigation augmented by magnetic resonance angiography when necessary. It is also apparent that surgical intervention should be performed only in highly selected patients without severe cardiac risk and in a surgical environment with a track record of low operative mortality.

At present the question of what to do for patients with asymptomatic carotid artery disease remains open. Data on the natural course of the disease are contradictory, and, until recently, studies of operative intervention have been inconclusive. Early results from the ACAS study may well have made the clinician's decision more difficult. In 1993 Barnett and Haines advised clinicians not to rush the pace of change, reminding therapeutic enthusiasts of an old gardener's axiom, "Flowers do not grow more quickly if we pull on them."14 The ACAS study could also alienate referring groups traditionally wary of surgical intervention in carotid disease. In a recent editorial Warlow used a population based argument and discounted individual benefit, suggesting that surgery on patients with asymptomatic disease is inappropriate. ${ }^{15}$

Progress will depend on calm appraisal of the available data. The North American Symptomatic Carotid Endarterec- tomy Trial suggested that four carotid endarterectomies in symptomatic patients would prevent one stroke a year. ${ }^{2}$ The data from the ACAS study suggest that among asymptomatic people nearly 20 carotid endarterectomies would be needed to prevent one stroke in every five years. ${ }^{13}$ If clinicians are in doubt about whether to offer surgery to patients with asymptomatic disease, the management of choice is to investigate with duplex ultrasound scanning, select patients carefully, and enrol them in the European ACST trial.

Craig D Irvine is supported by the Stroke Association.

CRAIG D IRVINE

Research fellow in surgery

ROGER N BAIRD

Consultant surgeon

PETER M LAMONT

Consultant surgeon

Department of Surgery,

Royal Infirmary,

Bristol BS2 8HW

ALUN H DAVIES

Senior lecturer

Department of Surgery,

Charing Cross Hospital,

London W6 8RF

1 Eastcott HHG. Carotid endarterectomy: a mid-Atlantic view. $\mathrm{Br} f$ Surg 1986;73:865.

2 North American Symptomatic Carotid Endarterectomy Trial Collaborators. Beneficial effect of carotid endarterectomy in symptomatic patients with high grade stenosis. $N$ Engl $f \mathrm{Med}$ 1991;325:445.

3 European Carotid Surgery Trialists' Collaborative Group. MRC European carotid surgery trial: interim results for symptomatic patients with severe $(70-99 \%)$ or with mild $(0-29 \%)$ stenosis.

4 Baird RN, Lambert M. Controversies in management. Should carotid endarterectomy be purchased? $B M \mp$ 1995;310:315.

5 Timsit SG, Sacco RL, Mohr JP, Foulkes MA, Tatemichi TK, Wolf PA, et al. Early clinical differentiation of cerebral infarction from severe atherosclerosis and cardioembolism. Stroke 1992;23:486.

6 Chambers BR, Norris JW. The case against surgery for asymptomatic carotid stenosis. Stroke 1984;15:605.

Autret A, Pourcelot L, Saudeau D, Marchal C, Bertrand P, de Boisuilliers S. Stroke risk in patients with carotid stenosis. Lancet 1987 ; i:888.

8 Moore WS, Barnett HLM, Taylor DW, Beebe HG, Bernstein EF, Brener BJ, et al. Guidelines for carotid endarterectomy. Stroke 1995;26:188.

9 Thompson JE, Patman RD, Talkington CM. Asymptomatic carotid bruit: long-term outcome of patients having carotid endarterectomy compared with controls. Ann Surg 1978;188:308

10 CASANOVA Study Group. Carotid surgery versus medical therapy in asymptomatic carotid stenosis. Stroke 1991;22:1229.

11 Mayo Asymptomatic Carotid Endarterectomy Study Group. Effectiveness of carotid endarterectomy for asymptomatic carotid stenosis: design of a clinical trial. Mayo Clin Proc 1989;64:897.

12 Hobson RW (II), Weiss DG, Fields WS, Goldstone J, Moore WS, Towne JB, et al. Efficacy of carotid endarterectomy for asymptomatic carotid stenosis. $N$ Engl f Med 1993;328:221.

13 Executive Committee for the Asymptomatic Carotid Atherosclerosis Study. Endarterectomy for asymptomatic carotid artery stenosis. $\mathcal{F} A M A$ 1995;273:1421.

14 Bamett HJ, Haines SJ. Carotid endarterectomy for asymptomatic carotid stenosis [editorial comment]. N Engl f Med 1993;328:276.

15 Warlow C. Endarterectomy for asymptomatic carotid stenosis. Lancet 1995;345:1254.

\section{Hunger strikes}

\section{Can the Dutch teach us anything?}

A hunger strike "is an age-old ritual act which can serve so many motivations and exigencies that it can be as corrupt as it can be sublime" noted Erikson in his study of Gandhi's nonviolent tactics. ${ }^{1}$ Within the past few years there have been well publicised hunger strikes for various causes in many countries, including the United States, the former Soviet Union, China, South Africa, Sudan, Poland, the former Yugoslavia, Bangladesh, France, Egypt, Canada, Israel, and the Netherlands.

Although deaths are rare, the power of the hunger strike comes from the striker's sworn intent to die a slow death in public view unless those in power address the injustice or condition being protested about. Hunger strikers are not suicidal and would greatly prefer responses to their demands.
The most intractable hunger strikes, from a human rights and medical ethics perspective, are those carried out by people in the custody of the state, usually in prisons or other detention centres. In this context deaths have occurred-most notably those of 10 Irish hunger strikers in Maze prison in Northern Ireland in 1981.

Hunger strikers present two primary ethical issues for doctors-when is it ethical to force feed a competent adult hunger striker and when is it ethical to artificially provide nutrition to a hunger striker who has become incompetent or unconscious? Medical groups have provided conflicting ethical advice on the first issue and virtually no guidance on the second. American courts have ruled that a prisoner who is on a hunger strike to obtain a transfer or for better living 